\title{
INFLUENCE OF SUB-ZERO TREATMENT IN LIQUID HELIUM AND TEMPERING ON THE MICROSTRUCTURE OF TOOL STEEL VANADIS 6
}

\author{
Jana PTAČINOVÁ, Juraj ĎURICA, Peter JURČl, Martin KUSÝ \\ Institute of Materials Science, Faculty of Materials Science and Technology in Trnava, Slovak Republic, EU \\ jana.ptacinova@stuba.sk
}

https://doi.org/10.37904/metal.2019.708

\begin{abstract}
Influence of sub-zero treatment and tempering on the microstructure of $\mathrm{Cr}$ - $\mathrm{V}$ ledeburitic steel Vanadis 6 has been examined. The samples were austenitized at the temperature of $1050{ }^{\circ} \mathrm{C}$ in a vacuum furnace, held at the final temperature for $30 \mathrm{~min}$. and nitrogen gas quenched (5 bar). In SZT, conventionally heat treated specimens were cooled down immediately after quenching from the room temperature to the temperature of liquid helium $\left(-269^{\circ} \mathrm{C}\right)$, kept there for $17 \mathrm{~h}$ and then re-heated to the room temperature. Double tempering was performed at the temperatures from the range $170-530^{\circ} \mathrm{C}$, whereas each tempering cycle was realized with a hold of $2 \mathrm{~h}$. Typical heat treated microstructure of ledeburitic steels consists, besides of the martensitic matrix with certain amount of retained austenite, of several types of carbides - eutectic, secondary and small globular carbides. In sub-zero treated steel the amount of retained austenite is significantly reduced. The population density of small globular carbides increases as a result of sub-zero treating as - possibly due to high internal stresses in martensite and material efforts of their relaxation. Tempering of the material resulted in decrease in population density of small globular carbides with increasing the tempering temperature. The hardness of sub-zero treated material is higher than that of conventionally quenched one. Also, this tendency is preserved when the steel is low-temperature tempered. On the other hand, the hardness of conventionally quenched steel becomes higher than that of SZT one when tempered at the temperature of secondary hardening.
\end{abstract}

Keywords: Ledeburitic steel, sub-zero treatment, martensite, retained austenite, carbides

\section{INTRODUCTION}

Cr- and Cr-V ledeburitic steels are extensively used in modern tooling where high compressive strength together with wear resistance and toughness are required [1]. Chromium-vanadium ledeburitic steels contain the chromium, typically $6-12$ wt $\%$ and also a large amount of vanadium. Vanadium, together with carbon, forms stable, very hard wear-resistant carbides of MC-type. The second main carbide in the Cr-V ledeburitic steels is the chromium-based $\mathrm{M}_{7} \mathrm{C}_{3}$. These steels have to be heat treated to obtain the above mentioned properties. Conventional heat treatment $(\mathrm{CHT})$ of these type of ledeburitic steels comprises vacuum austenitizing, hold at the desired temperature, nitrogen gas quenching, and tempering. After the quenching, the $\mathrm{Cr}-\mathrm{V}$ ledeburitic steels contain martensite $\left(\alpha^{\prime}\right)$, retained austenite $(\mathrm{YR})$, and undissolved carbides. In some cases, also a certain portion of bainite was detected, but it does not have detrimental effect on hardness. Subzero treatment (SZT) is a supplementary process to the conventional heat treatment of the steels, which can play an important role in the finishing of tools and components, where high wear resistance, dimensional stability and hardness are required. In this step of the heat treatment, the materials are immersed immediately after quenching into suitable cryo-processing media for pre-determined time and re-heated to a room temperature. After SZT, the tempering should be carried out in order to reduce internal stresses formed during cooling and to induce transformations in the martensite and retained austenite (if any $Y_{R}$ is presented in the microstructure). Sub-zero treatment provides positive changes in properties, which can be summarized as follows: The wear performance is improved due to SZT for AISI D2 ledeburitic steel [2,3] as well as for the D3 steel [4-7]. Information on the effect of SZT on toughness and fracture toughness is different depending on the type of tempering. Usually the higher $\mathrm{K}_{\mathrm{IC}}$ is observed for lower hardness and lower $\mathrm{K}_{\mathrm{IC}}$ for elevated hardness 
for the same tool steel. In other words, the application of SZT decreases the $\mathrm{K}_{\mathrm{Ic}}$ when the steel is low temperature tempered. Very interesting phenomenon has been observed for the material tempered at the usual secondary hardening temperature; the $\mathrm{K}_{\mathrm{IC}}$ was higher for the SZT material [8]. The as-SZT hardness is expectedly higher than that after conventional heat treatment, however, the hardness of the materials decreases more rapidly in SZT steels during tempering $[9,10]$. Referred changes in properties of SZT ledeburitic steels are attributed to microstructural alternations such as: reduction or almost complete removal of the $Y_{R}$ [5-7]; extensive plastic deformation of virgin martensite, which results in capture of carbon atoms by moving dislocations [11]; accelerated precipitation rate of nanosized carbides, due to the abovementioned phenomena $[4,8,12]$ (however, this is not entirely clear yet because some authors [13] have reported opposite results; higher population density of small carbides in as-tempered SZT material $[5,14]$. The current paper deals with the characterization of microstructure of sub-zero treated PM ledeburitic steel Vanadis 6 whereas the sub-zero treatment has been completed in liquid helium for $17 \mathrm{~h}$. Tempering behaviour of sub-zero treated steel is also described. The results are compared to the same material after conventional quenching.

\section{MATERIAL AND EXPERIMENTAL METHODS}

\subsection{Material and processing}

The experimental material was the P/M ledeburitic steel Vanadis 6 with nominally (in wt\%) $2.1 \mathrm{C}, 1.0 \mathrm{Si}, 0.4$ $\mathrm{Mn}, 6.8 \mathrm{Cr}, 1.5 \mathrm{Mo}, 5.4 \mathrm{~V}$ and $\mathrm{Fe}$ as balance. The samples were heat treated using following schedules: heating to the austenitizing temperature $1050^{\circ} \mathrm{C}$ in a vacuum furnace, hold at the final temperature for $30 \mathrm{~min}$. and nitrogen gas quenching ( 5 bar). In SZT, conventionally heat treated specimen were cooled down immediately after quenching from the room temperature to the temperature of liquid helium $\left(-269^{\circ} \mathrm{C}\right)$, kept there for $17 \mathrm{~h}$ and then re-heated to the room temperature. Double tempering was performed at the temperatures from the range $170-530^{\circ} \mathrm{C}$, whereas each tempering cycle was realized with a hold of $2 \mathrm{~h}$.

\subsection{Experimental methods}

Metallographical samples were prepared by standard preparation line and etched with a Villela-Bain reagent. For the precise investigations of microstructure, the scanning electron microscopy has been used. For the scanning electron microscopy (SEM), a JEOL JSM 7600F apparatus, equipped with an EDS-detector Oxford Instruments, has been employed whereas the microstructure was recorded using the secondary electron (SE) detection regime. Hardness of the material in the as-received as well as heat processed conditions was measured by the Vickers method on hardness tester Zwick 3212 (HV10). Each specimen was measured 5 times. The mean value and standard deviation from the measurements of each specimen was calculated. The amount of retained austenite was measured by X-ray diffraction, according to the ASTM E975-13 standard [15]. X-ray patterns were recorded using Phillips PW 1701 device with filtered Coa1,2 characteristic radiation, in the range $20-144^{\circ}$ of the two-theta angle.

\section{RESULTS}

\subsection{Microstructure}

SEM micrographs, Figure 1, show an example of microstructure evolution of the material after quenching and sub-zero treatment in liquid helium (for $17 \mathrm{~h}$ ) and tempering at different temperatures. Figures $1 \mathrm{a}$ and $\mathbf{1 b}$ show representative micrographs of conventionally hardened specimen and sub-zero treated one. The microstructure manifests uniform distribution of carbides throughout the matrix in both cases. Microstructure contains 3 types of carbides: eutectic, secondary and small globular carbides. The amount of small globular carbides increases with the application of sub-zero treatment. The matrix is composed of the martensite and the retained austenite. The character of matrix microstructure changes with increasing of the tempering 
temperature expectedly, Figures 1c-f. Due to the tempering, the martensite becomes more sensitive to the etching agent (so-called tempered martensite). This is commonly known fact and it is referred to precipitation of carbides during tempering. Retained austenite is transformed to martensite. The portion of carbides is also changed due to the tempering.

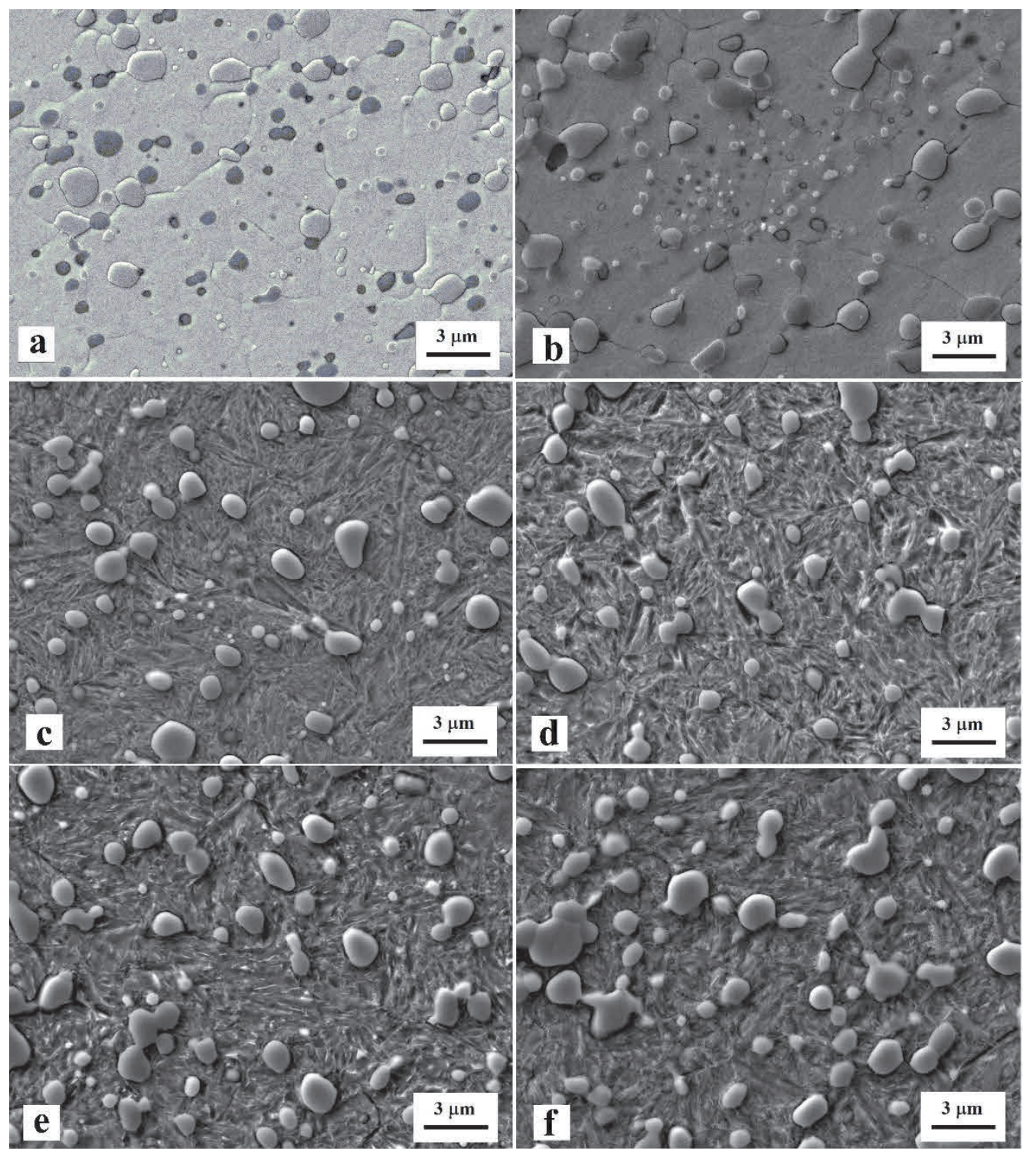

Figure 1 SEM micrographs showing the microstructure of Vanadis 6 ledeburitic steel after quenching (a), subsequent SZT (b) and tempering at (c) $-170^{\circ} \mathrm{C}$, (d) $-330^{\circ} \mathrm{C}$, (e) $-450{ }^{\circ} \mathrm{C}$, (f) $-530^{\circ} \mathrm{C}$.

\subsection{Population density of small globular carbides}

For quantification of carbides, the scanning electron microscopy was used. The aim was to determine whether the amount of small globular carbides undergoes changes in course of the tempering. For the categorization of the carbide particles, the results of the investigation published by Bílek et al. [16] were used. According to these results, the particles were categorized as eutectic carbides (MC-phase, vanadium - based, formations with a size $>1 \mu \mathrm{m})$, secondary carbides $\left(\mathrm{M}_{7} \mathrm{C}_{3}\right.$-phase, chromium - based, formations with a size $\left.>0.5 \mu \mathrm{m}\right)$ and small globular carbides (EDS-microanalysis did not give a doubtless answer regarding their nature), size $<0.5$ $\mu \mathrm{m}$, mostly around $0.1 \mu \mathrm{m}$. On each specimen, twenty randomly acquired micrographs have been used for the investigations. Amount of carbides was determined manually. 


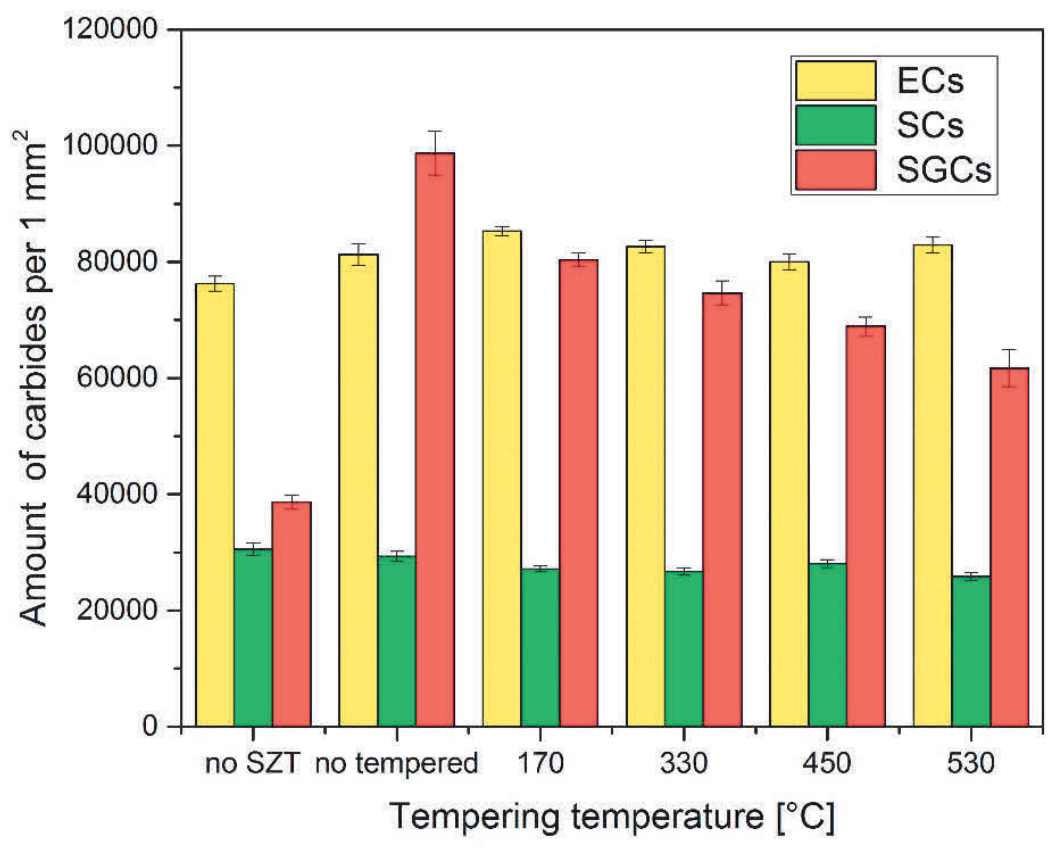

Figure 2 Amount of carbides in Vanadis 6 steel sub-zero treated for 17 hours in liquid helium regarding to tempering temperature

Figure 2 shows that the tempering induces a rapid decrease of the amount of SGCs. The mean values of population density of these particles for no tempered samples and samples tempered at 170, 330, 450, and $530{ }^{\circ} \mathrm{C}$ were $98.10^{3} / \mathrm{mm}^{2}, 80.10^{3} / \mathrm{mm}^{2}, 74.10^{3} / \mathrm{mm}^{2}, 68.10^{3} / \mathrm{mm}^{2}$ and $61.10^{3} / \mathrm{mm}^{2}$, respectively. Here it should be mentioned that tempering is always associated with reduction of internal stresses developed by quenching and/or sub-zero treatment. One can thus expect that the driving force for formation of SGCs would be reduced at the same time. In addition, tempering of martensite induces precipitation of carbides and lowering of its tetragonality, which is connected with increase of the specific density of the martensite. Based on this consideration it can be hypothesized that the SGCs originated due to SZT can be partially dissolved and thereby their amount decreases with increasing the tempering temperature.

\subsection{Amount of retained austenite}

The amount of retained austenite is presented in Table 1 (vol.\%). The amount of retained austenite decrease relatively rapidly with the application SZT. In no-SZT sample $\gamma_{R}$ amount was 20.2 vol.\% and for SZT sample with $17 \mathrm{~h}$ holding time it was just $6.8 \mathrm{vol} . \%$. The fact that the sub-zero treatment reduces the $\mathrm{YR}_{\mathrm{R}}$ amount is generally accepted and is attributed to the use of processing temperature below the characteristic $\mathrm{M}_{\mathrm{f}}$ temperature.

Table 1 Amount of retained austenite in Vanadis 6 ledeburitic steel after different regimes of heat treatment

\begin{tabular}{|c|c|c|c|c|c|c|}
\hline $\begin{array}{c}\text { Heat } \\
\text { treatment }\end{array}$ & $\begin{array}{c}\text { Conventional } \\
\text { heat } \\
\text { treatment }\end{array}$ & $\begin{array}{c}\text { SZT in liquid } \\
\text { helium }\end{array}$ & $\begin{array}{c}\text { SZT + } \\
\text { tempered at } \\
\mathbf{1 7 0}{ }^{\circ} \mathbf{C}\end{array}$ & $\begin{array}{c}\text { SZT + } \\
\text { tempered at } \\
\mathbf{3 3 0} \mathbf{C}\end{array}$ & $\begin{array}{c}\text { SZT + } \\
\text { tempered at } \\
\mathbf{4 5 0} \mathbf{~}^{\circ} \mathbf{C}\end{array}$ & $\begin{array}{c}\text { SZT + } \\
\text { tempered at } \\
\mathbf{5 3 0}\end{array}$ \\
\hline $\begin{array}{c}\text { Amount of } Y_{R} \\
\text { [vol. \%] }\end{array}$ & 20.2 & 6.8 & 6.5 & 5.6 & b.d.l. & b.d.l. \\
\hline
\end{tabular}

In SZT specimens, the $\mathrm{Y}_{\mathrm{R}}$ percentage slightly decreases already at lower tempering temperatures. Corresponding amounts of $\gamma_{R}$ are $6.5 \mathrm{vol} . \%$ and 5.6 vol. \% for tempering temperatures of 170 and $330^{\circ} \mathrm{C}$. At higher tempering temperatures the amount of $Y_{R}$ decreases very rapidly, and the specimens are almost free of $Y_{R}$ after tempering (amount of retained austenite is below of detection limit of device). 


\subsection{Hardness characteristics}

The bulk hardness of no SZT and SZT Vanadis 6 steel, as a function of tempering temperature, is shown in Table 2. The as-quenched hardness for conventionally heat treatment steel which was no tempered was $838 \pm 4 \mathrm{HV} 10$. The hardness of the SZT steel soaked in liquid helium for 17 hours and no tempered was correspondingly higher, e.g. $904 \pm 5$ HV10. These results show that the as-quenched bulk hardness of the Vanadis 6 steel is improved due to the sub-zero treatment. The hardness of all the samples then decreases with increasing the tempering temperature. Here it is interesting that the hardness of the SZT steel remains higher up to the tempering temperature of $450{ }^{\circ} \mathrm{C}$ and then drops down more intensively than that of conventionally quenched samples. As a result the hardness of the specimens tempered in the range of temperatures commonly used for secondary hardening is lower for SZT steel than what is achieved after conventional quenching and tempering.

Table 2 Hardness of Vanadis 6 ledeburitic steel after different regimes of heat treatment

\begin{tabular}{|c|c|c|c|c|}
\hline \multirow{2}{*}{ Tempering of samples } & \multicolumn{2}{|c|}{ CHT } & \multicolumn{2}{|c|}{ SZT } \\
\cline { 2 - 5 } & HV10 & \pm & HV10 & I \\
\hline no tempered & 838 & 4 & 804 & 5 \\
\hline tempered at $170{ }^{\circ} \mathrm{C}$ & 784 & 7 & 811 & 4 \\
\hline tempered at $330^{\circ} \mathrm{C}$ & 736 & 3 & 780 & 4 \\
\hline tempered at $450^{\circ} \mathrm{C}$ & 724 & 6 & 706 & 4 \\
\hline tempered at $530^{\circ} \mathrm{C}$ & 758 & & & 5 \\
\hline
\end{tabular}

\section{CONCLUSIONS}

The obtained experimental results lead to following major conclusions:

- Sub-zero treatment results in more complete martensitic transformation, enhanced number and population density of small globular carbides, having a size between 100 and $500 \mathrm{~nm}$, and in overall refinement of the microstructure.

- The number of small globular carbides decreases with the application of the tempering treatment. The higher the tempering temperature the decrease of carbides count is more significant.

- The amount of retained austenite slightly decreases up to a tempering temperature of $330^{\circ} \mathrm{C}$. At higher tempering temperatures the amount of $\gamma_{R}$ decreases very rapidly, and the specimens are almost free of $Y_{R}$ after tempering.

- The as-quenched hardness of the Vanadis 6 steel manifests a moderate increase due to the sub-zero treatment in liquid helium. As-tempered hardness is generally determined by competitive effect of the tempering of the martensite, transformation of retained austenite, SGCs count, and precipitation of special carbides. The hardness of all the samples then decreases with increasing the tempering temperature. The hardness of the SZT steel remains higher up to the tempering temperature of $450{ }^{\circ} \mathrm{C}$ and then drops down more intensively than that of conventionally quenched samples. As a result the hardness of the specimens tempered in the range of temperatures commonly used for secondary hardening is lower for SZT steel than what is achieved after conventional quenching and tempering.

\section{REFERENCES}

[1] JURČI, P., DOMÁNKOVÁ, M., ČAPLOVIČ, L'., PTAČINOVÁ, J., SOBOTOVÁ, J., SALABOVÁ, P., PRIKNER, O., ŠUŠTARŠIČ, B. and JENKO, D. Microstructure and hardness of sub-zero treated and no tempered P/M Vanadis 6 ledeburitic tool steel. Vacuum. 2015. vol. 111, pp. 92-101. 
[2] DAS, D., DUTTA, A.K. and RAY, K.K. Sub-zero treatments of AISI D2 steel: Part II. Wear behaviour. Mater. Sci. Engng. 2010. vol. A527, pp. 2194 - 2206.

[3] STRATTON, P.F. Optimising nano-carbide precipitation in tool steels. Mater. Sci. Eng.2007. vol. A449-451, pp. $809-812$.

[4] MOHAN LAL, D., RENGANARAYANAN, S. and KALANIHIDI, A. Cryogenic treatment to augment wear resistance of tool and die steels. Cryogenics. 2001. vol. 41, pp. $149-155$.

[5] AMINI, K., AKHBARIZADEH, A. and JAVADPOUR, S. Investigating the effect of the quench environment on the final microstructure and wear behaviour of 1.2080 tool steel after deep cryogenic heat treatment. Mater. Design. 2013. vol. 45, pp. 316 - 322.

[6] AKHBARIZADEH, A., AMINI, K.and JAVADPOUR, S. Effects of applying an external magnetic field during the deep cryogenic heat treatment on the corrosion resistance and wear behaviour of 1.2080 tool steel. Mater. Design. 2012. vol. 41, pp. 114 - 123.

[7] AMINI, K., AKHBARIZADEH, A. and JAVADPOUR, S. Investigating the effect of holding duration on the microstructure of 1.2080 tool steel during the deep cryogenic treatment. Vacuum. 2012. vol. 86, pp. 1534 - 1540.

[8] SOBOTOVÁ, J., JURČI, P. and DLOUHÝ, I. The effect of subzero treatment on microstructure, fracture toughness, and wear resistance of Vanadis 6 tool steel, Mater. Sci. Eng.2016. vol. A652, pp. 192 - 204.

[9] BERNS, H. Restaustenit in ledeburitischen Chromstählen und seine Umwandlung durch Kaltumformen, Tiefkühlen und Anlassen. HTM. 1974. vol. 29, no. 4, pp. 236 - 247.

[10] PELLIZZARI, M., MOLINARI, A. Deep Cryogenic Treatment of Cold Work Tool Steel. In: the 6th Int. Tooling Conf. Karlstad University: J. Bergstrom, G. Fredriksson, M. Johansson, O. Kotik, F. Thuvander, 2002, pp. 547 - 558.

[11] TYSHCHENKO, A.I., THEISEN, W., OPPENKOWSKI, A., SIEBERT, S., RAZUMOV, O.N., SKOBLIK, A.P., SIROSH, V.A.,PETROV, J.N. and GAVRILJUK, V.G. Low-temperature martensitic transformation and deep cryogenic treatment of a tool steel. Mater. Sci. Eng.2010. vol. A527, pp. 7027 - 7039.

[12] COLLINS, D.N. and DORMER, J. Deep Cryogenic Treatment of a D2 Cold-Work Tool Steel. Heat Treatment of Metals. 1997.vol. 24, pp. 71 - 74.

[13] GAVRILJUK, V.G. THEISEN, W., SIROSH, V.V., POLSHIN, E.V., KORTMANN, A., MOGILNY, G.S., PETROV, YU.N. and TARUSIN, Y.V. Low-temperature martensitic transformation in tool steels in relation to their deep cryogenic treatment. Acta Mater. 2013. vol. 61, pp. 1705 - 1715.

[14] DAS, D. and RAY, K.K. Structure-property correlation of sub-zero treated AISI D2 steel. Mater. Sci. Eng.2012. vol. A541, pp. 45 - 60.

[15] ASTM E975-13: Standard Practice for X-Ray Determination of Retained Austenite in Steel with Near Random Crystallographic Orientation, In: ASTM Book of Standards, vol. 3.01, West Conshohocken, PA, USA, 2004.

[16] BÍLEK, P., SOBOTOVÁ, J. and JURČI, P. Materiali in Tehnologije. Materials and Technology. 2011. vol. 44, PP. 33-37. 